\title{
Velocity Monitoring of Molten Steel in a Continuous Casting Mold Using Three Submerged Entry Nozzle Designs
}

\author{
Raul Miranda1, Miguel A. Barron², Carlos A. Hernandez² \\ ${ }^{1}$ Departamento de Electronica, Universidad Autonoma Metropolitana Azcapotzalco, Ciudad de Mexico, Mexico \\ ${ }^{2}$ Departamento de Materiales, Universidad Autonoma Metropolitana Azcapotzalco, Ciudad de Mexico, Mexico \\ Email: bmma@correo.azc.uam.mx
}

How to cite this paper: Miranda, R., Barron, M.A. and Hernandez, C.A. (2016) Paper Title. Modeling and Numerical Simulation of Material Science, 6, 59-68. http://dx.doi.org/10.4236/mnsms.2016.64006

Received: October 13, 2016

Accepted: December 23, 2016

Published: December 28, 2016

Copyright $\odot 2016$ by authors and Scientific Research Publishing Inc. This work is licensed under the Creative Commons Attribution International License (CC BY 4.0). http://creativecommons.org/licenses/by/4.0/

\begin{abstract}
The horizontal and vertical velocity components of molten steel in a slab continuous casting mold produced by three different two-port Submerged Entry Nozzle (SEN) designs are monitored and compared using Computational Fluid Dynamics (CFD) simulations. These two ports designs correspond to a conventional cylindrical SEN, a plate SEN and an anchor-shaped SEN. Four monitoring points at the molten steel in the centered vertical plane were selected to track the horizontal and the vertical component of the velocity vector. Two of them are located near the free surface and the remaining two are located in the vicinity of the SEN discharge nozzles. Some statistical values of the time series of above the velocity components are analyzed and correlated with the Kelvin-Helmholtz instability and the Karman vortex streets, which cause mold powder entrapment in the molten steel.
\end{abstract}

\section{Keywords}

Computational Fluid Dynamics, Continuous Casting, Molten Steel,

Mold Powder Entrapment, Submerged Entry Nozzle, Velocity Monitoring

\section{Introduction}

In the continuous casting of steel, molten steel is fed from a ladle into a mold through a Submerged Entry Nozzle (SEN). In contact with the water-cooled walls of the mold, molten steel forms a solidified shell. At the exit of the mold, the steel product ends its solidification by means of water sprays. A powder is fed at the top of the mold in order to provide lubrication to the mold walls, avoiding in this way adherence of the solidified shell at the mold walls, which in turn causes the unwanted sticking breakout phe- 
nomenon. At the same time, the powder protects molten steel from atmospheric oxidation and prevents premature solidification. Unfortunately, sometimes the powder becomes entrapped in the molten steel, and as a consequence, the solid steel product exhibits low quality in the form of poor mechanical properties.

It is widely accepted that the quality of the continuous-cast products is severely affected by the fluid flow in the mold and the SEN design, and that sudden transients are responsible of flow instabilities that cause surface turbulence [1]. In accordance to [2], powder entrainment is influenced, among other factors, by rapid mold level fluctuations, surface waves, SEN design and shallow SEN immersion. A Computational Fluid Dynamics (CFD) study on mold powder entrapment caused by vortexing flow at the interface between mold powder and molten steel near the SEN is reported in [3]. Mold properties, mainly viscosity, prevent the entrapment phenomenon in ultra-low carbon steels [4]. More specifically, mold powder entrapment is enhanced by Kelvin-Helmholtz instability (KHI) [5] [6] and Karman vortex streets (KVS) [4] [6]. KHI is present in the powder-molten steel interface, and it is recognized that KHI represents an imbalance of the destabilizing effect of inertia of a light phase (powder) moving in the horizontal direction over the stabilizing effect of buoyancy of a heavy phase (molten steel) [7]. Meanwhile, in the mold KVS are generated behind the SEN in the downward vertical direction [6], and they arise when the velocity goes beyond certain excitation value [8].

In this work the horizontal and vertical velocity components of molten steelproduced by three different SEN designs are monitored and compared using CFD simulations. These SEN have been previously characterized by the present authors in terms of free surface topography, velocity vector and turbulent intensity [9]. The considered twoport SEN designs are shown in Figure 1. The first one (Figure 1(a)) corresponds to a conventional cylindrical SEN (hereinafter called conventional), the second one (Figure 1(b)) corresponds to a SEN with an oval plate located in its upper part (hereinafter called plate), and finally, an anchor-shaped SEN (hereinafter called anchor). The SEN dimensions are [9]: $0.5 \mathrm{~m}$ high, 0.06 mnozzle innerdiameter, 0.04 mnozzle dischargeport diameter, plate thickness $0.02 \mathrm{~m}$.

Four monitoring points in the molten steel were selected to track the horizontal and

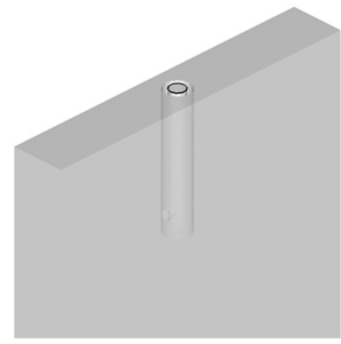

(a)

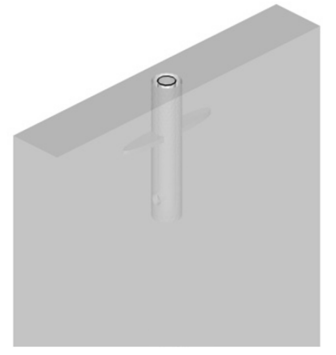

(b)

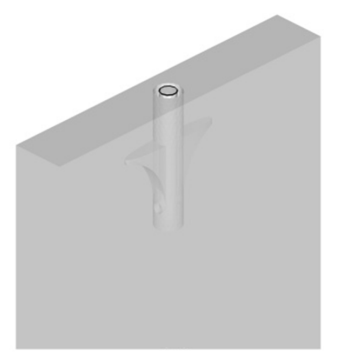

(c)

Figure 1. The considered Submerged Entry Nozzles: (a) conventional cylindrical; (b) plateshaped; (c) anchor-shaped [9]. 
the vertical component of the velocity vector: Two of them near the free surface and the remaining two in the vicinity of the SEN discharge nozzles.

\section{Mathematical Model}

Mathematically, the flow of an isothermal incompressible Newtonian fluid and the mass conservation are represented by the Navier-Stokes equations and the continuity equation [10]. These equations come from force balances and mass conservation, respectively. To maintain the mass balance in the system, the continuity equation must be solved too. Turbulence is simulated by means of the classical two equations K- $\varepsilon$ model [11]. For the pressure-velocity coupling, the Pressure-Implicit with Splitting of Operators (PISO) algorithm is employed [12]. Besides, the Volume of Fluid (VOF) model is employed to issue the multiphase flow. VOF is based on the assumption that two or more phases are not interpenetrating [12] [13]. For each additional phaseq, its volume fraction $\alpha_{\mathrm{q}}$ is introduced as a variable. In each control volume the volume fractions of all phases sum to unity [12]. The tracking of the interface between the phases is accomplished by solving the continuity equation for each phase [12] [13].

\section{Model Solution and Velocity Monitoring}

Transient 3-D two-phase (air-molten steel) isothermal computer simulations were carried out with time steps of $0.001 \mathrm{~s}$ using Computational Fluid Dynamics software. The value of the time step was determined from numerical experiments, and corresponds to that value which gives numerical stability. $100 \mathrm{~s}$ of integration time was assumed to yield fully developed flow of molten steel in the mold volume. The mold dimensions were: height, $2 \mathrm{~m}$; width, $1.2 \mathrm{~m}$; thickness, $0.2 \mathrm{~m}$. The initial level of molten steel was $1.82 \mathrm{~m}$, and the remaining volume of the mold was air. The considered physical properties of molten steel were: density of $7100 \mathrm{~kg} / \mathrm{m}^{3}$ and viscosity of $0.0067 \mathrm{~kg} /(\mathrm{m} . \mathrm{s})$. Boundary conditions were as follows: velocity inlet $2.83 \mathrm{~m} / \mathrm{s}$, which corresponds to a casting speed of $1.5 \mathrm{~m} / \mathrm{min}$; turbulent kinetic energy $0.08 \mathrm{~m}^{2} / \mathrm{s}^{2}$, turbulent dissipation rate $0.755 \mathrm{~m}^{2} / \mathrm{s}^{3}$. The computational mesh employed in the computer simulations contains 464,000 tetrahedral/hybrid cells. The mesh and the coordinate system employed in the computer simulations are shown in Figure 2.

For velocity analysis, four monitoring points were selected as tracking locations at the $\mathrm{Y}=0$ vertical plane. The $(\mathrm{X}, \mathrm{Y}, \mathrm{Z})$ coordinates of these points were as follows: A $(-0.24,0.0,0.8), \mathrm{B}(0.24,0.0,0.8), \mathrm{C}(-0.075,0.0,0.65), \mathrm{D}(0.075,0.0,0.65)$, and their approximate location is depicted in Figure 3 . The points A and B are symmetrical, and are located at $0.02 \mathrm{~m}$ from the initial level of molten steel with the purpose of tracking the horizontal $(\mathrm{X})$ velocity component and the vertical $(\mathrm{Z})$ velocity component of the molten steel velocity vector near the free surface. On the other hand, the $C$ and $D$ points are located $0.17 \mathrm{~m}$ below the molten steel surface in order to track the $\mathrm{X}$ and $\mathrm{Z}$ velocity components in opposite places near the SEN discharge ports. Using the above data, the mean residence time (MRT) of molten steel in the mold is $72.8 \mathrm{~s}$. To obtain re- 

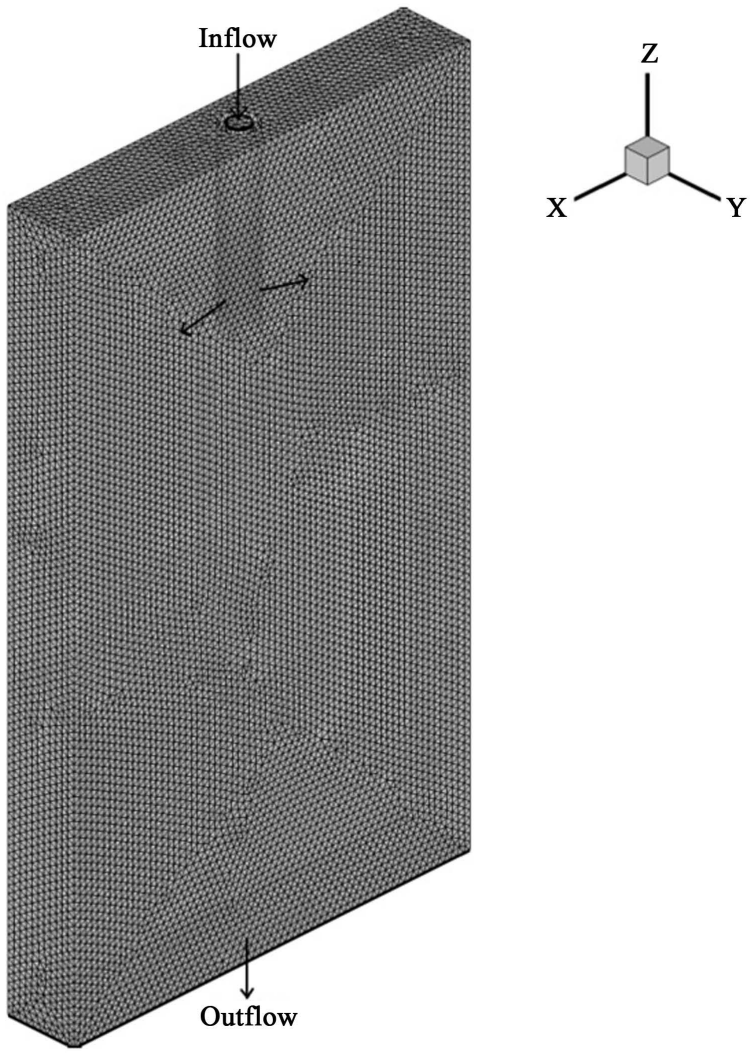

Figure 2. The computational mesh and the coordinate system employed in the computer simulations [9].

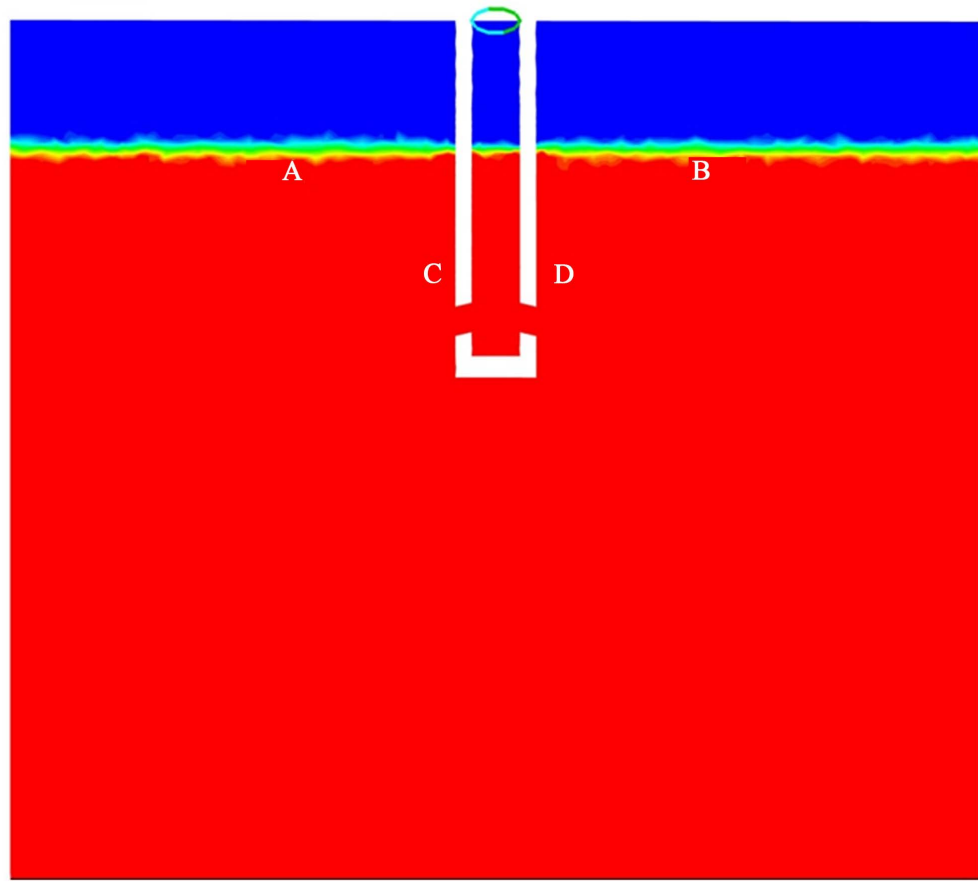

Figure 3. Location of the monitoring points at the $\mathrm{Y}=0$ vertical plane for the conventional SEN. Red phase is molten steel, blue phase is air. 
liable and representative results and analysis of velocity monitoring, computer runs spanned from $100 \mathrm{~s}$, which corresponds to fully developed flow, to $180 \mathrm{~s}$, which corresponds to around 2.5 times the MRT of molten steel.

\section{Results}

As was explained before, the $\mathrm{X}$ and $\mathrm{Z}$ components of the vector velocity of molten steel are associated with the magnitude of the Kelvin-Helmholtz instability and the Karman vortex streets, respectively. In this Section the tracked results of these velocity components in the chosen monitoring points from $100 \mathrm{~s}$ to $180 \mathrm{~s}$ of elapsed time are presented and discussed.

Figure 4 shows the time series of the $\mathrm{X}$ velocity component for the three SEN considered at the $\mathrm{A}$ and $\mathrm{B}$ monitoring points, which are located just $0.02 \mathrm{~m}$ below the molten

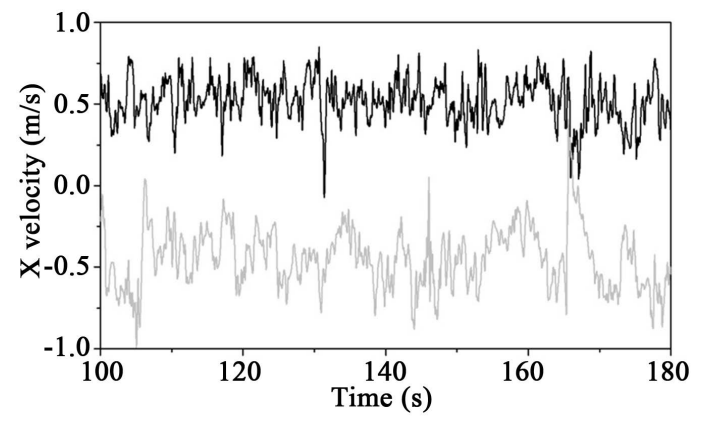

(a)

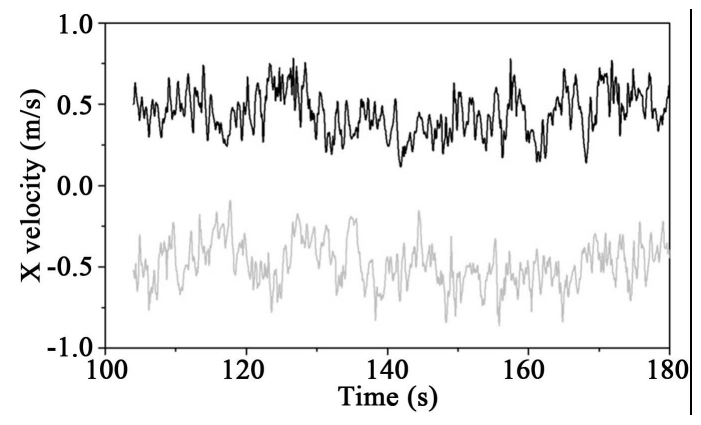

(b)

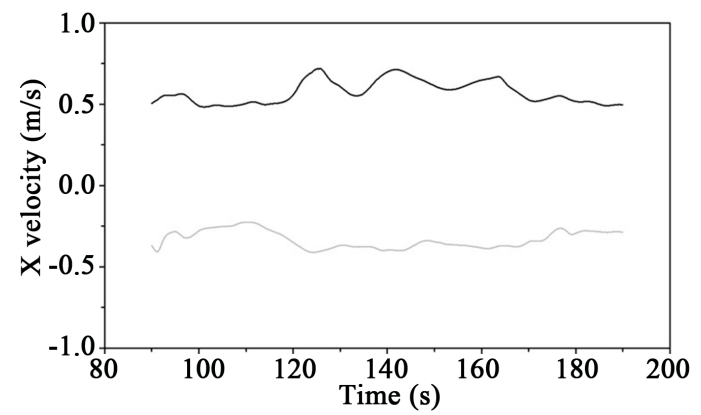

(c)

Figure 4. Time evolution of the $\mathrm{X}$ component of the velocity vector for (a) simple; (b) plate; and (c) anchor SEN. Monitors: A (black), B (gray). 
steel free surface, as is seen in Figure 3. The three SEN present positive values of $X$ velocity component at $\mathrm{A}$, whereas they exhibit negative values of the $\mathrm{X}$ velocity component at $\mathrm{B}$. This is explained by the fact that the flow of molten steel is directed towards the SEN, driven by the recirculation loops in the upper part of the mold [14] [15], as is observed in Figure 5 for the anchor SEN. Table 1 shows some statistics (minimum, maximum and mean values) of the time series of Figure 4 . These values suggest that significant asymmetry in the molten steel flow is present on the left and right sides of the mold. The asymmetry of the molten steel flow in the left and the right parts of the mold has been reported at least two decades ago [14]. This asymmetry is quantitatively verified by observing the different statistic values of the $\mathrm{X}$ velocity component of Table 1 .

In accordance to Table 1, the plate SEN presents the lowest average value $(0.4480$ $\mathrm{m} / \mathrm{s}$ ) of the X velocity component at the A monitoring point, whereas the anchor SEN shows the lowest average absolute value $(0.3324 \mathrm{~m} / \mathrm{s})$ of this component at the B monitoring point. The conventional SEN exhibits the highest maximum $\mathrm{X}$ velocity $(0.9082$ $\mathrm{m} / \mathrm{s}$ ) among the three considered SEN. Related to the $\mathrm{Z}$ component of the vector velocity, is the anchor SEN who exhibits the lowest average absolute value $(0.0025 \mathrm{~m} / \mathrm{s})$ at both monitoring points, as is seen in Table 2.

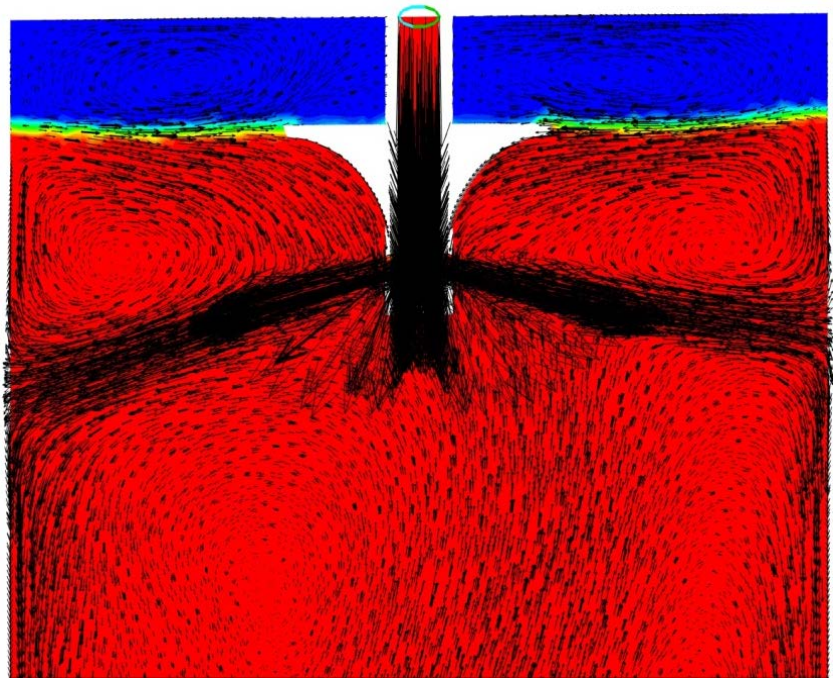

Figure 5. Velocity vectors in the $\mathrm{Y}=0$ vertical plane corresponding to the anchor-shaped SEN.

Table 1. Statistics of the time series of the $\mathrm{X}$ velocity component at $\mathrm{A}$ and $\mathrm{B}$ monitoring points.

\begin{tabular}{ccccccc}
\hline \multirow{2}{*}{$\begin{array}{c}\text { Value } \\
(\mathrm{m} / \mathrm{s})\end{array}$} & \multicolumn{2}{c}{ Conventional SEN } & \multicolumn{2}{c}{ Plate SEN } & \multicolumn{2}{c}{ Anchor SEN } \\
\cline { 2 - 7 } & $\mathrm{A}$ & $\mathrm{B}$ & $\mathrm{A}$ & $\mathrm{B}$ & $\mathrm{A}$ & $\mathrm{B}$ \\
\hline Minimum & -0.0721 & -0.9908 & -0.0241 & -0.8612 & 0.4827 & -0.4410 \\
Maximum & 0.9082 & 0.4038 & 0.8281 & -0.0917 & 0.7201 & -0.2247 \\
Span & 0.9803 & 1.3946 & 0.8522 & 0.7695 & 0.2374 & 0.2163 \\
Average & 0.5177 & -0.4456 & 0.4480 & -0.4774 & 0.5739 & -0.3324 \\
\hline
\end{tabular}


Table 2. Statistics of the time series of the Z velocity component at A and B monitoring points.

\begin{tabular}{ccccccc}
\hline \multirow{2}{*}{$\begin{array}{c}\text { Value } \\
(\mathrm{m} / \mathrm{s})\end{array}$} & \multicolumn{2}{c}{ Conventional SEN } & \multicolumn{2}{c}{ Plate SEN } & \multicolumn{2}{c}{ Anchor SEN } \\
\cline { 2 - 7 } & $\mathrm{A}$ & $\mathrm{B}$ & $\mathrm{A}$ & $\mathrm{B}$ & $\mathrm{A}$ & $\mathrm{B}$ \\
\hline Minimum & -0.3737 & -0.4334 & -0.2059 & -0.2529 & -0.0249 & -0.0703 \\
Maximum & 0.4206 & 0.6622 & 0.2367 & 0.1562 & 0.0327 & -0.0059 \\
Span & 0.7943 & 1.0956 & 0.4426 & 0.4091 & 0.0576 & 0.0644 \\
Average & -0.0301 & -0.0247 & -0.0161 & -0.0275 & -0.0025 & -0.0025 \\
\hline
\end{tabular}

As was stated in Section 1, mold powder entrapment is enhanced by the KelvinHelmholtz instability (KHI) and the Karman vortex streets (KVS). The magnitude of the $\mathrm{KHI}$ is proportional to the horizontal (X) component of the velocity vector in the vicinity of the molten steel free surface, whereas the magnitude of the KVS is proportional to the downward vertical $(\mathrm{Z})$ component of the vector velocity in the vicinity of the SEN discharge. In order to carry out a qualitative evaluation of the KHI and the KVS, in Figure 6 and Figure 7 the $\mathrm{X}$ and $\mathrm{Z}$ components of the vector velocity are monitored and depicted. Figure 6 shows a direct comparison of the $\mathrm{X}$ component of the vector velocity for each SEN considered at the A and B monitoring points. It is clearly observed that the anchor SEN presents the more stable and smooth time evolution of the $\mathrm{X}$ component at both monitoring points. On the other hand, in Figure 7 depicts the time series of the $\mathrm{Z}$ component of the vector velocity for each SEN at the $\mathrm{C}$ and $\mathrm{D}$ monitoring points. As the case of Figure 6, the anchor SEN exhibits the smooth time evolution at the $\mathrm{C}$ and $\mathrm{D}$ monitoring points. Some statistics of the times series of Figure 7 are presented in Table 3. In accordance with this table, is the conventional cylindrical SEN who exhibits the lowest and the largest values of the absolute values of the minimum and maximum $\mathrm{Z}$ velocity component.

\section{Conclusions}

Three different designs of Submerged Entry Nozzles (SEN) were presented here. Their performances are numerically studied and compared in terms of the time series of the $\mathrm{X}$ and $\mathrm{Z}$ components of the vector velocity at four monitoring points. From the numerical results the following conclusions arise:

i) The plate and the anchor SEN present the lowest absolute average values of the $\mathrm{X}$ (horizontal) components of the vector velocity at the monitoring points located in the vicinity of the molten steel free surface.

ii) The plate and the anchor SEN present the lowest absolute average values of the $Z$ (vertical) components of the vector velocity at the monitoring points located in the vicinity of the SEN discharge nozzles.

iii) The conventional cylindrical SEN exhibits the largest absolute values of the minimum and maximum $\mathrm{X}$ and $\mathrm{Z}$ components of the vector velocity at the four monitoring points. 


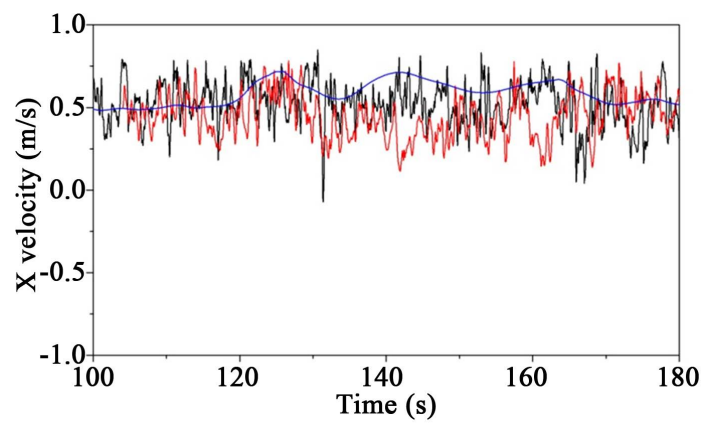

(a)

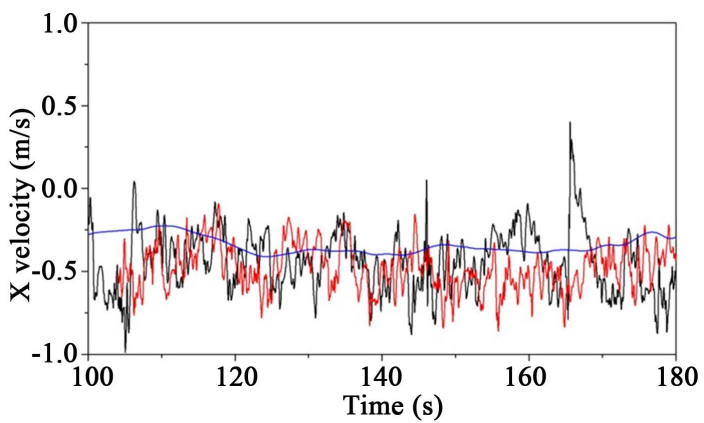

(b)

Figure 6. Time evolution of the X component of the velocity vector. Monitors: (a) A; (b) B. SEN: simple (black), plate (red), anchor (blue).

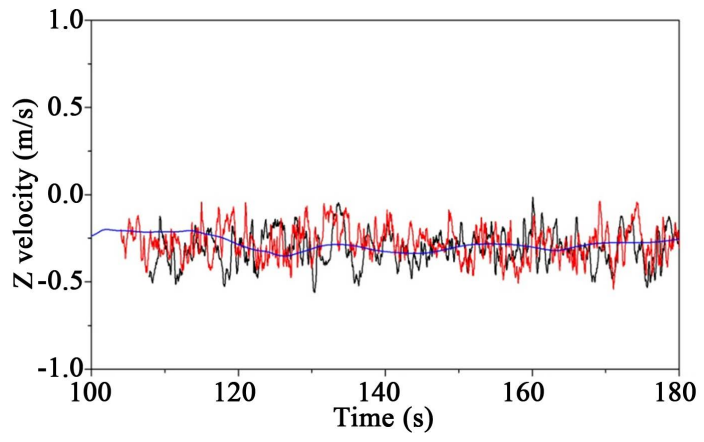

(a)

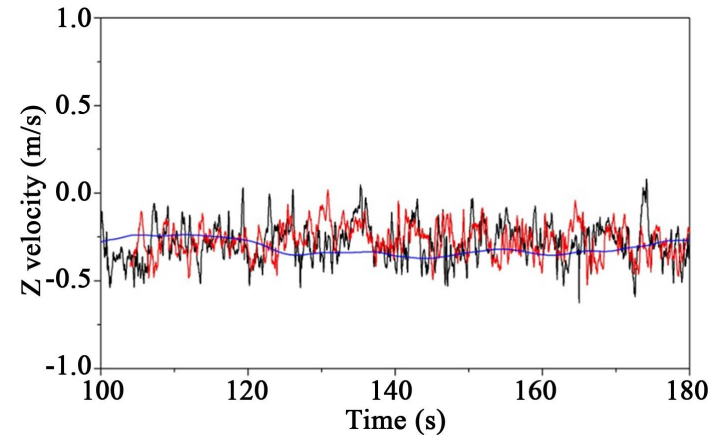

(b)

Figure 7. Time evolution of the $\mathrm{Z}$ component of the velocity vector. Monitors: (a) C; (b) D. SEN: simple (black), plate (red), anchor (blue). 
Table 3. Statistics of the time series of the $\mathrm{Z}$ velocity component at $\mathrm{C}$ and $\mathrm{D}$ monitoring points.

\begin{tabular}{ccccccc}
\hline \multirow{2}{*}{$\begin{array}{c}\text { Value } \\
(\mathrm{m} / \mathrm{s})\end{array}$} & \multicolumn{2}{c}{ Conventional SEN } & \multicolumn{2}{c}{ Plate SEN } & \multicolumn{2}{c}{ Anchor SEN } \\
\cline { 2 - 6 } & $\mathrm{C}$ & $\mathrm{D}$ & $\mathrm{C}$ & $\mathrm{D}$ & $\mathrm{C}$ & $\mathrm{D}$ \\
\hline Minimum & -0.6362 & -0.6260 & -0.5431 & -0.5232 & -0.3512 & -0.3725 \\
Maximum & 0.0385 & 0.0791 & -0.0306 & 0.0175 & -0.1995 & -0.2378 \\
Span & 0.6747 & 0.7051 & 0.5125 & 0.5407 & 0.1517 & 0.1347 \\
Average & -0.2971 & -0.2859 & -0.2815 & -0.2726 & -0.2756 & -0.3055 \\
\hline
\end{tabular}

iv) Given that the $\mathrm{X}$ and $\mathrm{Z}$ components of the vector velocity are associated with the Kelvin-Helmholtz instability and the Karman vortex streets, respectively, it is the conventional cylindrical SEN who is more prone to present mold powder entrapment.

\section{References}

[1] Thomas, B.G. (2005) Modeling of Continuous Casting Defects Related to Mold Fluid Flow. 3 rd International Congress on Science \& Technology of Steelmaking, Charlotte, 9-12 May 2005, 847-861.

[2] Scoones, D., Thornton, S., Spierings, A. and Moonen, W. (1994) Improvement in Mold Powder Supply, Performance and the Mechanism of Slag Entrapment in the Solidifying Strand during Casting. Report EUR 17883, European Commission, 9-14.

[3] Kastner, G., Brandstaetter, W., Kaufmann, B. and Javurek, M. (2006) Numerical Study on Mold Powder Entrapment Caused by Vortexing in a Continuous Casting Process. Steel Research International, 77, 404-408. https://doi.org/10.1002/srin.200606406

[4] Watanabe, K., Tsutsumi, K., Suzuki, M., Nakada, M. and Shiomi. T. (2009) Effect of Properties of Mold Powder Entrapped into Molten Steel in a Continuous Casting Process. ISIJ International, 49, 1161-1166. https://doi.org/10.2355/isijinternational.49.1161

[5] Hibbeler, L.C. and Thomas, B.G. (2010) Investigation of Mold Flux Entrainment in cc Molds Due to Shear Layer Instability. AISTech 2010, Pittsburgh, 4-7 May 2010, 1-16.

[6] Ueda, Y., Kida, T. and Iguchi, M. (2004) Unsteady Pressure Coefficient around an Elliptic Immersion Nozzle. ISIJ International, 44, 1403-1409.

https://doi.org/10.2355/isijinternational.44.1403

[7] Drazin, P.G. and Reid, W.H. (2004) Hydrodynamic Stability. 2nd Edition. Cambridge University Press, Cambridge, UK, 14-22. https://doi.org/10.1017/CBO9780511616938

[8] Vad, J., Lajos, T. and Schilling, R., Eds. (2004) Modelling Fluid Flow, The State of the Art. Springer Verlag, Berlin, 183.

[9] Hernandez, C.A., Miranda, R. and Barron, M.A. (2016) Numerical Comparison of the Performance of Submerged Entry Nozzles for Slab Continuous Casting. WorldComp 2016: The 2016 International Conference on Modeling, Simulation and Visualization Methods (MSV2016). Las Vegas, 25-28 July 2016, 74-77.

[10] Bird, R.B., Stewart, W.E. and Lightfoot, E.N. (2002) Transport Phenomena. 2nd Edition, Wiley, New York, 843-851.

[11] Thomas, B., Yuan, Q., Sivaramakhrisnan, S., Shi, T., Vanka, S.P. and Assar, M.B. (2001) Comparison of Four Methods to Evaluate Fluid Velocities in a Continuous Slab Casting Mold. ISIJ International, 41, 1262-1271. https://doi.org/10.2355/isijinternational.41.1262

[12] Fluent 6.1. User's Guide. Lebanon, NH, 2003. 
[13] Hirt, C.W. and Nichols, B.D. (1981) Volume of Fluid (VOF) Method for the Dynamics of Free Boundaries. Journal of Computational Physics, 39, 201-225. https://doi.org/10.1016/0021-9991(81)90145-5

[14] Gupta, D., Chakraborty, S. and Lahiri, A.K. (1997) Asymmetry and Oscillation of the Fluid Flow Pattern in a Continuous Casting Mould: A Water Model Study. ISIJ International, 37, 654-658. https://doi.org/10.2355/isijinternational.37.654

[15] Thomas, B.G. and Zhang, L. (2001) Mathematical Modeling of Fluid Flow in Continuous Casting. ISIJ International, 41, 1181-1193. https://doi.org/10.2355/isijinternational.41.1181

Submit or recommend next manuscript to SCIRP and we will provide best service for you:

Accepting pre-submission inquiries through Email, Facebook, LinkedIn, Twitter, etc. A wide selection of journals (inclusive of 9 subjects, more than 200 journals)

Providing 24-hour high-quality service

User-friendly online submission system

Fair and swift peer-review system

Efficient typesetting and proofreading procedure

Display of the result of downloads and visits, as well as the number of cited articles Maximum dissemination of your research work

Submit your manuscript at: http://papersubmission.scirp.org/

Or contact mnsms@scirp.org 